\title{
Digital Education For All: Better Students Through Open Doors?
}

\section{Pirttinen, Nea}

ACM

2021-06-26

Pirttinen , N , Leinonen , J \& Lemström , K 2021 , Digital Education For All: Better Students Through Open Doors? in Proceedings of the 26th Annual Conference on Innovation and Technology in Computer Science Education. ACM , New York, United States , pp. 450-456, Annual Conference on Innovation and Technology in Computer Science Education , Paderborn , Germany , 28/06/2021 . https://doi.org/10.1145/3430665.3456327

http://hdl.handle.net/10138/333454

https://doi.org/10.1145/3430665.3456327

acceptedVersion

Downloaded from Helda, University of Helsinki institutional repository.

This is an electronic reprint of the original article.

This reprint may differ from the original in pagination and typographic detail.

Please cite the original version. 


\section{Digital Education For All: Better Students Through Open Doors?}

\author{
Nea Pirttinen \\ nea.pirttinen@helsinki.f \\ University of Helsinki \\ Helsinki, Finland
}

\author{
Juho Leinonen \\ juho.leinonen@helsinki.f \\ University of Helsinki \\ Helsinki, Finland
}

\author{
Kjell Lemström \\ kjel.lemstrom@helsinki.f \\ University of Helsinki \\ Helsinki, Finland
}

\begin{abstract}
TheDigital Education For All project (DEFA) is a joint collaboration of $f$ ve universities to open $f$ rst-year computer science courses onlineand for freeto audiences outsideof universities. Additionally, students who complete enough courses through the project can apply for a study right at any of the participating universities.

Completing university courses as a method of applying for a study right measures students' motivation over a long period of time, and gives the students a clear idea of the content they will encounter during their studies, whereas a traditional entrance exam measures competence only at a single point in time. While high school grades, another typical intake mechanism besides entrance exams, measure generic study skills, course-based intake mechanisms may help with student retention, as students express and gain interest in the f eld while completing the required courses.

This study is a preliminary examination of the student intake of the DEFA project in the University of Helsinki, one of the participating universities, and a comparison of how the students accepted through the project perform in studies compared to students accepted through other intakemechanisms. Students wishing to apply for a study right through this intake are expected to complete one regular study year's worth of $f$ rst-year computer science and mathematics courses in approximately one calendar year.
\end{abstract}

\section{CCSCONCEPTS}

-Social and professional topics $\rightarrow$ Computing education.

\section{KEYWORDS}

admission policies, retention in computer science, intake mechanisms, student intake, student admissions

ACM Reference Format:

Nea Pirttinen, Juho Leinonen, and Kjell Lemström. 2021. Digital Education For All: Better Students Through Open Doors?. In 26th ACM Conference on Innovation and Technology in Computer Science Education V. 1 (ITiCSE 2021), fune 26-fuly 1, 2021, Virtual Event, Germany. ACM, New York, NY, USA, 7 pages. https://doi.org/10.1145/3430665.3456327

\footnotetext{
Permission to make digital or hard copies of all or part of this work for personal or classroom use is granted without fee provided that copies are not made or distributed for prof $\mathrm{t}$ or commercial advantage and that copies bear this notice and the full citation on the f rst page Copyrights for components of this work owned by others than the author(s) must behonored. Abstracting with credit is permitted. To copy otherwise, or republish, to post on servers or to redistributeto lists, requires prior specif c permission and/or a fee. Request permissions from permissions@acm.org.

ITiCSE 2021, June 26-fuly 1, 2021, Virtual Event, Germany

C 2021 Copyright held by the owner/author(s). Publication rights licensed to ACM. ACM ISBN 978-1-4503-8214-4/21/06...\$15.00

https://doi.org/10.1145/3430665.3456327
}

\section{INTRODUCTION}

The usual Bachelor's degree in Finland is 180 ECTS $^{1}$ credits. The Finnish government has set a 3-year target time for graduation; this target inf uences both the students and the education provider. Students can receive f nancial support during their studies, and the support has two parts: a monthly grant and a governmentguaranteed loan. The grant can be received for up to 30 months for the Bachelor's degree. The loan also includes a built-in incentive for in-timegraduation: if the degree is completed within thetarget time, up to a third of the loan may be compensated.

There is al so a built-in incentive to meet the graduation target time for the education provider. The Finnish government started a new funding model for universities in $2021^{2}$. There are three main parts in the model: 1) education, 2) research and 3) other education and science policy considerations with weighting factors $42 \% 34$ $\%$ and $24 \%$ respectively. Within the education part, the f nancial focus and the aforementioned built-in incentive comes from the number of completed degrees: the number of degrees completed within thetarget time or within 12 months after thetarget time will be compensated with weighting factors of 1.5 and 1.3 , respectively.

The normal intake mechanism to tertiary education in Finland is via a nationwide joint application system. In this system, applicants rank up to six education providers in a decreasing order based on their interest. When they score enough entrance points for any of the education providers in their list, they are given the opportunity to enrol in the one with the highest rank in thelist. In this system, the entrance points are based on success either in the matriculation examination taken in the f nal year of high school studies (with certain discipline weighting factors) or in a separate entrance exam. The main shortcoming of this mechanism is that it ostracises individuals suf ering from stress in an examination situation. Moreover, as computer science has traditionall ly not been taught in high schools in Finland, many people either do not apply in thef rst place because they do not know the discipline, or discontinue their studies having had a false impression of what computer science really is like.

Another intake mechanismin the University of Helsinki is via Open University. A student completing the basic studies module (25 credits) of computer science within 3 years and with a weighted grade point average (GPA) of at least 3.5/5 is entitled to enrol in the Bachelor's programme. Our programme, however, has of ered extra intake mechanisms.

\footnotetext{
${ }^{1}$ European Credit Transfer and Accumulation System, in which each credit corresponds to approximately 27 hours of work, and 60 ECTS credits to full year of studies. ${ }^{2}$ Theprinciples of themodel can befound here: https://minedu.f /en/steering-f nancingand-agreements.
} 
In 2012, we started a MOOC path where the students had to complete two courses (introduction and advanced course in programming, $5+5$ credits) in 14 weeks $[11,20]$. Any student managing to complete $90 \%$ out of the weekly assignments throughout the courses was invited to an exam. The top 50 students of the exam were given a permission to enrol in the computer science programme. Over time, this path became highly popular, ending up in a situation where this path got more competitive than the joint application system. Moreover, as the path became more and more populated by people al ready in the job market who only had the interest of the benef ts of a student status and no plans to complete their degree, we decided to replace that path with another one, hopefully better targeted to motivated students.

In 2017, we began a 3-year-long pilot project with four other universities, supported by the Ministry of Education. The aim of the Digital Education For All project (DEFA) is to open computer science studies to everyone, and to try a new intake mechanism favouring hard-working students. As the f ve participating universities are rather dif erent in the application popularity and number of annual intakes, each participating university planned their own requirements for intake. We decided to of er the right to enrol to any student completing 50 (only in the f rst year of the project) or 60 credits of our MOOC courses within a calendar year. This corresponds to a full year of studies in the ECTS.

The Finnish government has taken several measures in order to lower theaverageageboth of students starting and completing their university studies. One specif c feature of computer science is that students are desperately wanted in the job market, and ther efore widely employed in an early phase of their studies, resulting in a long tail in the graduation distribution.

By of ering a new intake mechanism, we aim at $f$ nding good, motivated students who hopefully graduate younger and in less time. In this paper, we report preliminary results on whether the new DEFA intake mechanism meets these goals.

This paper is organised as follows. Section 2 reviews common university admission policies and computer science student retention. Section 3 describes the context of thestudy, as well as the data and research methods used. In Section 4, we present the results of this study, which are then discussed in Section 5. Finally, we summarise the work and outline future directions in Section 6.

\section{RELATED WORK}

Admission policies vary from university to university. Most com monly, students are required to have successfully completed primary and secondary level education to be eligibleto attend tertiary education, i.e university studies. However, sincetypically only a limited number of students can be accepted due to resource constraints, tertiary educational institutions often consider additional merits such as secondary education (eg. high school) grades, or rank students based on scores from university entrance examinations.

Aspects that have been considered in university admissions include, for example, entrance examinations specif c to the university or study program [6], national or universal entrance examinations where students apply to multiple universities or programs at the same time [1, 2], high school grades [15], standardized tests taken by high school students (eg. the SAT and ACT exams) [15], extracurricular activities (eg. activity in student clubs) [9], motivation letters/essays [5], and recommendation letters [10]. All of these measure dif erent aspects of potential students and universities often take multiple aspects into account in their admissions. Some are entirely merit-based and objective such as standardized test scores or high school grades whereas others are more subjective such as motivation essays and recommendation letters.

In Europe, most universities are publicly funded [8]. Thus, in somecountries, public authorities have a say on how many students areadmitted to specif c university degreeprograms [17]. Pruvot and Estermann [17] categorize European university admission policies into three models based on who decides on the policy: 1) universities, 2) external authorities, or 3) co-regulated by universities and external authorities together. Countries where universities can freely decide admission policies include, for example, the UK, Ireland, Finland, Poland and Italy. Countries whereexternal authorities decide admission policies indude, for example, France, Belgium, Switzerland and Austria. Many countries also have free admission policies, meaning that generally all students who wish to enrol in universities areallowed to do so [17] - these include, for example, the Netherlands, France, Belgium, Switzerland and Austria.

Comparing open admissions to selective, competitive admissions, one major limitation of open admissions is that a larger student body requires more resources from the university. On the other hand, tertiary institutions usually get more resources if they can attract morestudents, for example, more tuition fees or more government funding. Nguyen and Lewis found that the presence of competitive enrollment policies, i.e requiring an application or certain grades, for computer science programs negatively predict students' sense of belonging, self-ef cacy and perception of the department being applied to [14]. They suggest that competitive enrollment policies may thus have unintended consequences. Re garding open admissions, the US National Center for Education Statistics reports that tertiary institutions with open admission policies report lower graduation rates compared to more selective institutions [7].

STEM (Science, Technology, Engineering, and Mathematics) subjects, and especially computer science have often been claimed to have high dropout rates [12, 16, 19]. In computer science, it has been found that globally, around one third of students fail theintroductory programming course [3, 21], which could partly explain the high dropout rates in CS programs: students who do not pass the introductory programming course are unlikely to continue in the computer science degree since it is usually a requirement for more advanced courses. The high dropout rates could al so be partly explained by students' lack of understanding what the CS programmeentails. Thus, it is important to study alternative intake methods that could help bring in motivated students who end up completing their degrees. In this article, we study how students accepted to a CS undergraduate programmethrough an alternative intake method based on motivation and inspired by open admission policies perform in their studies compared to students accepted through traditional admission pathways. 


\section{METHODOLOGY}

\subsection{Context}

Thestudy was conducted at the Department of Computer Science at the University of Helsinki, a public research-f rst university in Finland. Students apply for a combined Bachelor's and Master's degree programme, and choose their major at the time of application. The Bachelor's degree consists of 180 ECTS credits with a target schedule of three years, while the Master's degree is 120 ECTS credits with a target schedule of two years. Thus, students are expected to complete approximately 60 ECTS credits each year. Thef rst year of the Bachelor's degreeis mostly computer science and mathematics courses with a heavy focus on programming and introductory topics such as databases.

Most of the students enter the computer science programme through what we call the "main intake", which consists of two possible intake routes: an entrance exam or high school matriculation examination grades. The computer science programme also used to have a third intake route for the main intake, a MOOC intake described in [11, 20], and similar to [13]. The MOOC intake has since been discontinued, but is included in the data set for the sake of comparison. Besides these, the programme has also admitted a small population of students through open university courses.

The DEFA project is an extension of the open university intake Students applying to the University of Helsinki through the DEFA project are expected to complete a year's worth of studies relevant to computer science. There are 30 credits of basic courses that are mandatory, including 5 credits of mathematics and 25 credits of computer science, while the rest of the required credits can be collected froma wide variety of computer science, mathematics and statistics courses. The project of ers almost 60 courses for freefrom $f$ ve universities, totaling in over 200 credits. The of ered courses are mostly online, with a few exceptions when it comes to exams. All the course content of ered through the DEFA project is comparable, and in some cases identical, to the courses university students take.

The DEFA intake does not have a grade average requirement instead, thestudents haveto complete the required number of credits in one calendar year, al lowing them to complete courses from the beginning of July until the end of June. The courses completed for the application are accepted as is for the degree after receiving a study right, meaning that the students accepted through the DEFA intake ef ectively start their studies from the second year.

The idea behind the conception of the DEFA project is to reach more motivated applicants who also will have a clear grasp of the requirements and the content of university and computer science studies when at the very beginning of their studies. Our hope is that these students would be less likely to drop out of university. Compared to the main intake, the DEFA intake should also help thosestudents who do not perform well in entrance exams due to examanxiety, or havenot performed well in high school. TheDEFA intake makes it possible for thesestudents to show their motivation and capabilities in computer science through actual studies, and use this to acquire a study right.

\subsection{Data}

The data used for this study consists of study records containing all the courses a student has taken in the University of Helsinki.
Courses completed in the other universities participating in the DEFA project are not included in the data. From this data, weexamine the credits and grades accumulated during the $\mathrm{rst}$ two years of studies for students who have been accepted to the computer science programme in 2018 or 2019. For the DEFA students, the $f$ rst year of studies is theyear they partici pate in the DEFA courses, and the second year is their actual $\mathrm{f}$ rst year in the university.

For the purposes of this study, wehave def ned a DEFA student to be a student who has completed morethan 50 credits from the DEFA course list in a year, and has been accepted to the computer science programme immediately after their DEFA study year. We al so identif ed students who have most likely tried theDEFA project, but failed to complete the required credits within a year for the DEFA intake, and got accepted through some other intake mechanism. We have labeled these students who completed more than 30 credits as DEFA tried. This is to try to dif erentiate this group from open university intake, which al lows students three years to complete 25 credits of set basic computer science courses with a GPA of 3.5/5 to get a study right.

Besides the aforementioned intakemechanisms, weal so examine two other intake groups for comparison. The main intake consists of students who have received their study right either through an entrance exam or with their high school matriculation examination grades. This is the largest group in the data, and the students from this intake usually have very few, if any, courses completed at the time of the admission. In the years under study, the university also had a $M O O C$ intake, which allows students to complete a semester long programming $\mathrm{MOOC}$ and apply for the university if they succeed well enough [11, 20]. These students have at least 10 credits from the programming MOOC.

With this division, we end up with $\mathrm{f}$ ve intake groups with 437 students in total. The intake populations from our data for two years are as follows:

- DEFA: 28

- DEFA tried: 30

- Open university: 76

- Main: 253

- MOOC: 50

Table 1 shows the university-reported yearly intake numbers through each intake mechanism - $\mathrm{frst}$, the number of accepted students and then, the number of applicants in parentheses. These numbers are al so reported in Figures 1 and 2, for accepted and applied students respectively. During the application, students apply for either main or open intake, and they arefurther divided into the previously described intake groups later during the process. Thus, MOOC intake is reported as a part of main intake, whileDEFA is a part of the open university intake. The number of applicants for the open university and the DEFA intakes are the same, as they are reported as one, non-dif erentiated statistic.

Wecan seethat our division mechanismisnot completely precise when comparing the numbers listed above to the numbers in Table 1. We have removed students who registered as absentees from our data, which explains some of the dif erences. Besides this, students can apply through multiple intakes at the sametime, meaning that there are duplicates in the university-reported data. It should also benoted that only approximately $10 \%$ of the students who start the 


\begin{tabular}{l|llll} 
& Year & & & \\
\hline Intake & 2017 & 2018 & 2019 & 2020 \\
\hline Main & $157(1026)$ & $168(1256)$ & $179(1623)$ & $183(1689)$ \\
MOOC & $50(85)$ & $50(187)$ & $50(349)$ & $50(445)$ \\
Open university & $20(24)$ & $28(31)$ & $63(85)$ & $72(98)$ \\
DEFA & n/a & n/a & $19(85)$ & $16(98)$
\end{tabular}

Table 1: Number of students accepted (and applied) through each intake for years 2017 to 2020. DEFA intake is not available for years 2017 and 2018.

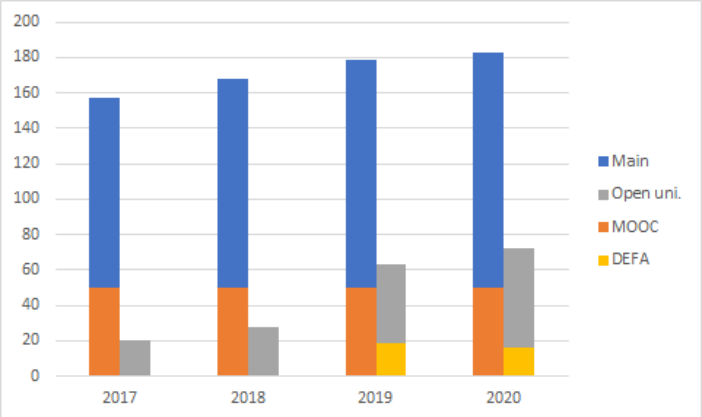

Figure 1: Number of students accepted through dif erent intake mechanisms.

MOOC persist through the course and apply through the MOOC intake, making the interest towards theintake seemlower than it is. The dif erences are mostly in the main and MOOC intakes, namely, it seems that some of the MOOC intake students end up in the main intake in our data. This causes no signif cant changes to our results, as the dif erences are relatively small and in cohorts that are very similar to each other demographics-wise. Additionally, this does not af ect the DEFA intake, which is the main intake under study.

\subsection{Research Methods}

\section{Our research questions are as follows:}

RQ1. How did the DEFA project af ect student intake in general?

RQ2. How do students accepted through the DEFA project perform in their studies compared to students accepted through other intake mechanisms?

Our research is based on a quantitative analysis of the intake reports and study transcripts. For the f rst research question, we examine the intake reports published by the university. We inspect the number of applying and accepted students, and brief y examine the age demographics of the latter group, as one of the government incentives is to encourage students to start their tertiary education earlier. For the second research question, data described in Section 3.2 is used to analyse the dif erences between students from dif erent intakes. We compare the completed credits and GPAs for the f rst two year of studies between students from dif erent intakes, focusing especially on comparing the DEFA intakestudents to main intakestudents, as they are the majority.

\section{RESULTS}

\subsection{Ef ect on Student Intake}

Results for the RQ1. How did the DEFA project affect student intake in general? are summarised in Table 1 , and Figures 1 and 2 . While the interest for the computer science programme has been growing

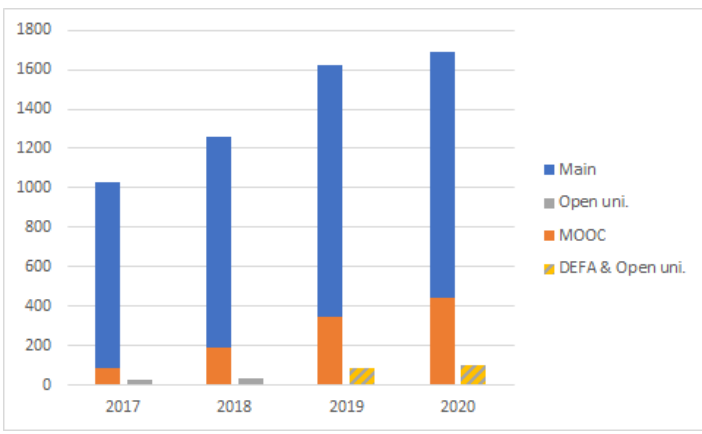

Figure 2: Number of students applied through dif erent intake mechanisms. Application information for the DEFA and open university intakes only available in one, nondif erentiated statistic.

\begin{tabular}{l|llllll}
\multicolumn{1}{l}{ Intake } & $\begin{array}{l}\text { GPA } \\
\text { total }\end{array}$ & $\begin{array}{l}\text { Credits } \\
\text { total }\end{array}$ & $\begin{array}{l}\text { Credits } \\
\text { Y1 }\end{array}$ & $\begin{array}{l}\text { Credits } \\
\text { Y2 }\end{array}$ & GPA Y1 & GPA Y2 \\
\hline DEFA & $4.2(0.5)$ & $92(27)$ & $57(11)$ & $38(24)$ & $4.3(0.5)$ & $4.1(0.5)$ \\
\hline DEFA tried & $4.1(0.6)$ & $98(30)$ & $50(22)$ & $67(4)$ & $4.0(0.8)$ & $4.0(1.4)$ \\
\hline Open uni. & $4.1(0.8)$ & $88(41)$ & $49(22)$ & $48(25)$ & $4.1(0.7)$ & $4.0(0.9)$ \\
\hline Main & $3.7(1.5)$ & $61(45)$ & $40(23)$ & $37(27)$ & $4.2(0.7)$ & $3.9(0.8)$ \\
\hline MOOC & $3.9(0.9)$ & $88(53)$ & $49(26)$ & $44(27)$ & $4.1(0.6)$ & $3.8(0.9)$
\end{tabular}

Table 2: Mean GPAs and credits in total over two years and by year of studies (Y1 for the f rst year, Y2 for the second). Standard deviation in parentheses.

rapidly, the ef ect of theDEFA project on theapplicants through the open university is clear. Even though theactual DEFA studentsform only a small portion of all the applicants, the number of students accepted through the open university intake has risen dramatically. It is possiblethat some of thesestudents havetried theDEFA project and dropped out at some point of their studies, opting for the open university intake instead, or that the students have learned about the open university intake through the media attention that the DEFA project has gained.

Not all students who get accepted necessarily decide to enrol at the university, which is why all the numbers presented in Table 1 areslightly higher than the actual number of students starting each year. Students can also apply through multiple intakes during the same year, causing some duplicate entries in the reported numbers.

As for the age demographics, we only took a cursory look into this part of data, and will leave a more throughout inspection for future work. However, it seems that the main and MOOC intakes have the youngest applicants, with a large portion of the students starting almost directly after high school at ages 19-20. For the main intake this is understandable, as it is most natural to take the entrance exam or apply using one's matriculation examination grades directly after graduating high school. For other intakes, the age demographics vary greatly, but theaverageage of thestudents is noticeably older, around 30 years old. Whilethe DEFA intake peaks at just after 20 years old and at 40 years old, the open university intake has a noticeable peak at 30.

\subsection{Performance Between Intake Groups}

Results for the RQ2. How do students accepted through the DEFA project perform in their studies compared to students accepted through other intake mechanisms? are summarised in Tables 2 to 4 . Table 2 shows thetotal mean GPA and credits for each intake over two 


\begin{tabular}{l|llll} 
& Credits & & & \\
Intake & CSY1 & CSY2 & Math Y1 & Math Y2 \\
\hline DEFA & $39(6)$ & $26(16)$ & $16(5)$ & $8(8)$ \\
\hline DEFA tried & $33(17)$ & $54(14)$ & $14(8)$ & $8(11)$ \\
\hline Open uni. & $30(15)$ & $29(12)$ & $14(10)$ & $13(14)$ \\
\hline Main & $26(15)$ & $21(17)$ & $12(8)$ & $11(10)$ \\
\hline MOOC & $31(16)$ & $28(21)$ & $14(11)$ & $13(8)$
\end{tabular}

Table 3: Average credits by subject for $f$ rst $(Y 1)$ and second (Y2) year of studies. Standard deviation in parentheses.

\begin{tabular}{l|llll} 
Intake & GPA & & & \\
\hline CSY1 & CSY2 & Math Y1 & Math Y2 \\
\hline DEFA tried & $4.2(1.2)$ & $4.5(1.1)$ & $4.6(1.0)$ & $4.4(0.8)$ \\
\hline Open uni. & $4.2(1.2)$ & $3.0(2.8)$ & $4.3(1.3)$ & $2.0(\mathrm{n} / \mathrm{a})$ \\
\hline Main & $4.4(1.1)$ & $3.9(1.2)$ & $4.2(1.1)$ & $4.0(1.4)$ \\
\hline MOOC & $4.4(1.0)$ & $3.8(1.4)$ & $3.7(1.2)$ & $4.1(1.2)$ \\
\hline
\end{tabular}

Table 4: Mean GPAs by subject for $f$ rst (Y1) and second (Y2) year of studies. Standard deviation in parentheses.

years, as well as the separated values for each year on their own. Table 3 has the average credits by subject, computer science or mathematics, for the f rst and second years separately. Similarly, Table 4 summarises the mean GPAs by subject for the $f$ rst and second years separately. In all the Tables 2 to 4, standard deviation is given in parentheses.

We applied the Mann-Whitney $U$ test to examine whether differences between groups are statistically signif cant. In order to avoid the multiple comparisons problem, the statistical tests were not run for all the possible combinations of intakes, but only for the most interesting comparisons.

When comparing the DEFA and the main intakes' credits, for year one Mann-Whitney test statistics $U=2575.0$ and $p=0.01$, meaning that the dif erence in credits between these intakes for the f rst year is statically signif cant. For the second year, $U=3126.0$ and $p=0.15$, meaning that the dif erence in credits for the second year is not statistically signif cant. The dif erence in GPAs for these intakes is not statistically signif cant for either of the years.

Looking at the completed credits from only computer science courses for the same intake mechanisms, for year one $U=2674.5$ and $p=0.02$, while for year two $U=3204.0$ and $p=0.20$. Thus, the dif erence in completed computer science credits between the intakes is statistically signif cant for the f rst year, but not for the second. As for the GPAs with the same parameters, for the r rst year $U=2474.5$ and $p=0.002$, while the second year is not statistically signif cant $(U=3323.5, p=0.30)$.

When comparing the yearly credits from DEFA intake to the open university intake, for the f rst year $U=807.5$ and $p=0.03$, and for the second year $U=824.0$ and $p=0.04$. Both of these results are statistically signif cant. For the computer science credits, the dif erence for the f rst year is statistically signif cant $(U=673.5$, $p=0.002)$, while the second year is not $(U=8525, p=0.06)$.

Finally, comparing the credits of students who got accepted through the DEFA project to those who tried the project, but ended up applying though some other intake mechanism (i.e the DEFA tried group), the dif erence in completed credits is statistically sig nif cant both for the f rst $(U=295.5, p=0.03)$ and the second year $(U=279.5, p=0.01)$. The dif erence in total credits is not
( $U=373.0, p=0.23)$, but since the standard deviation is high for both of the intakes $(s d=27$ for the DEFA and $s d=30$ for the DEFA tried group), it is dif cult to f nd statistical signif cance

\section{DISCUSSION}

The DEFA project has had a clear ef ect on the number of applicants and accepted students, especially when it comes to the open university intake, as seen in Table 1, and Figures 1 and 2. Open university courses have traditionally not been free, but most of the courses required for this intake became free because of the DEFA project. Thus, theDEFA project increases the applicants of theopen university intake in two ways: theopen university is not as costly as it used to be, and it becomes an attractive intake mechanism for students who drop out of the DEFA project as the course re quirements have some overlap. The DEFA project has also garnered some media attention, which has probably increased the visibility of the computer science programme in general, af ecting all the intakemechanisms, but especially theones relying on open courses, the DEFA and the open university intakes.

While the DEFA project has not achieved the goal of accepting younger students into the university earlier, it still serves as an intake mechanism that makes sure that the students accepted certainly know what computer science studies include. Thoseyounger students that did decide to participate in the DEFA project directly after high school and got accepted to the university did not essentially take any gap years, as they can begin their computer science studies directly from the second year courses after completing the DEFA intake requirements.

The DEFA students complete more credits during their $\mathrm{f}$ rst year than any other intake group, 57 credits on average This dif erence in credits is al so statistically signif cant when compared to the main and open university intakes. This is understandable, as the students have the pressure of completing enough credits during their DEFA year to gain the study right. While the DEFA students complete fewer credits during their second year, in total, they have as many credits completed as students from any other intake after two years of studies. Thus, it seems that the DEFA students are as successful as students from other intakes when it comes to completing courses. Sincestudents from other intakes complete fewer credits during their $f$ rst year, they are doing some of the courses the DEFA students took in their $\mathrm{f}$ rst year during their second year - thus, the DEFA students might be faring slightly better, as they have more advanced courses left for their second year.

Another reason why the DEFA students complete fewer credits during their second year may also bethat they either get or return into working lifefaster than other students. Sincethere is a shortage of computer science professionals in the job market in Finland, motivated and well-performing students tend to get hired as early as after their $f$ rst year of studies, which in turn slows down their studies during the second and third years of Bachelor's degree, and postpones graduation. We also noticed a peak in older students accepted through the DEFA project at around 40 years old. It is possible that these students have taken a study leave from their regular job, applied to the university through the DEFA intake, and are then continuing to work whilst also studying for a degree.

Interestingly, the students who tried the DEFA project but did not complete the requirements, the DEFA tried group, completed 
the most credits in total, 98 credits in two years. While the average credits for the f rst year in the DEFA tried group is in line with the other intakes at 50 credits, the second year's average of 67 is higher than usual. It is possible that thereare students in this group who have dropped out of the DEFA project relatively late, so they have partially completed some of the courses and have easier time with them during the second try. As the students in this group overall performed well, it seems that they did not drop out of the DEFA project due lack of motivation or skill. These students possibly decided that a full year of self-studies was not for them and decided to pursue some other intake mechanism, or they encountered some personal issues we cannot account for in this study.

The DEFA students have not only shown great skills in studying independently, but also interest and internal motivation to the subject, as is it unlikely that a student could complete a year's worth of credits only by self-studying while relying completely on external motivation of getting into the university, especially since there are less laborious intake mechanisms available, such as the open university intake. Our f ndings support this idea of motivation, as the DEFA students continue to perform well during their second year of the studies.

Since 2016, students who apply for tertiary education in Finland for thef rst time, that is, they have not had a study right to any university or college previously, have a priority in thestudent intake A signif cant portion of the allowed intake is limited to f rst-time applicants only. This has caused some students to hesitate when deciding what to study after high school, making the transition from one level of education to another a longer process - losing one's f rst-time applicant position makes applying for another ma jor much moredif cult. TheDEFA project allows studentsto sample a wide variety of computer science courses for free and with no repercussions regarding university applications. This makes it easier for the students to decide whether studying computer science is for them without losing their f rst-time applicant's position. If a student decides not to pursue a computer science degree, they can still use their completed credits in another degree.

TheDEFA project also opens up courses for other participants outsideof universities who haveno interest in applying for full-time education. As university-level courses, the DEFA project courses are suitablefor, for example, in-servicetraining and thosewho wish to hone their skills in computer science topics without a lasting commitment or a need for a degree. Our study only examines those who applied and got accepted into the university, and thus, students completing only a handful of courses got excluded from our data.

\subsection{Limitations}

Theresults of this study arespecif c to this particular context. There are study structure and country-specif c factors, such as student benef ts and government funding models, and one cannot draw direct conclusion to other contexts based on our results.

The DEFA project has been running only for a few years, and thus, the collected data is still limited. This study only strives to examine some preliminary results. Longer-term ef ects, such as the intake's ef ect on the graduation time, are still unknown and part of the future research endeavors.
Our data did not include credits completed in other universities, even though these credits could have been used at the application process, as long as they were completed from the DEFA course list within the given time constraints. Also, dividing thestudents based on their completed courses and credits is not completely accurate, and some students' intakes may have been categorized incorrectly.

\section{CONCLUSIONS}

In this work, we examined how students admitted to the computer science programme in the University of Helsinki perform during thef rst two years of their studies when compared to their peers accepted through other intake mechanisms. We also inspected the ef ect of the DEFA project on thestudent intake in general.

To summarise, weanswer our research questions as follows:

RQ1. How did the DEFA project af ect student intake in general? Answer: The DEFA project signif cantly increased the number of applicants and accepted students, af ecting especial ly the open university intake Moreover, the project seems to have a notableinf uence on the number of applicants in the main intake as well.

RQ2. How do students accepted through theDEFA project perform in their studies compared to students accepted through other intake mechanisms?

Answer: The students accepted through the DEFA project perform just as well in their studies as students accepted through other intake mechanisms, and complete more credits during their $\mathrm{f}$ rst year than other students.

While our study is context-reliant, it gives us more information on how intake mechanisms af ect student populations and their performance in general. This can be useful for other universities planning to change or expand their intake mechanisms.

For future work, we will look into student performance further as the DEFA students progress in their studies, as well as examine whether the dif erent intake mechanisms will also have an ef ect on whether the students complete their Bachelor's degree, and if they graduate within the target schedule. Wearealso interested in examining thestudent demographics further, as well as other factors that may inf uence study success between intake mechanisms, such as previous programming experience. Another research direction that we would like to pursue in the future is gathering information from the DEFA students of their experiences during theDEFA study year, and how well have they managed to integrate into university studies after receiving a study right.

We do not know the full ef ects of the COVID-19 situation on student performance, but based on various student well-being reports around the world, the ef ects will most likely show up in our future data. Whilesome students are ableto perform normally in their studies, at least in the beginning of the pandemic [4], the negative ef ects of isolation and thelongevity of the uncertain situation might have a negative impact on students' well-being [18].

\section{ACKNOWLEDGEMENTS}

This research was supported by a grant from the Finnish Ministry of Education and Culture, grant number OKM/248/523/2017.

We would like to thank Matti Luukkainen for feedback on the article and for help in acquiring the data used for this research. 


\section{REFERENCES}

[1] Kamal Abouchedid. 2010. UndergraduateAdmissions, Equity of Access and Quality in Higher Education: An International ComparativePerspective In Towards an Arab higher education space: international challenges and societal responsibilities: Proceedings of the Arab Regional Conference on Higher Education. UNESCO, 137.

[2] Muhammad AzeemAshraf. 2014. Chinese higher education enrollment policy: Fairness of system for students' choice of university. In 2014 International Conference on Global Economy, Finance and Humanities Research (GEFHR 2014). Atlantis Press.

[3] Jens Bennedsen and Michael E Caspersen. 2007. Failure rates in introductory programming. AcM SIGcSE Bulletin 39, 2 (2007), 32- 36.

[4] Vincenza Capone, Daniela Caso, Anna Rosa Donizzetti, and Fortuna Procentese 2020. University Student Mental Well-Being during COVID-19 Outbreak: What Are the Relationships between Information Seeking, Perceived Risk and Personal Resources Related to the Academic Context? Sustainability 12, 17 (Aug 2020).

[5] JessicaSinger Early, Meredith DeCosta-Smith, and Arturo Valdespino. 2010. Write Your Ticket to College: A Genre-Based College Admission Essay Workshop for Ethnically Diverse, Underserved Students. fournal of Adolescent \& Adult Literacy 54, 3(2010), 209-219.

[6] Daniel Edwards, Hamish Coates, and Tim Friedman. 2012. A survey of interna tional practice in university admissions testing. Higher Education Management and Policy 24, 1 (2012), 1-18.

[7] National Center for Education Statistics. 2020. Undergraduate retention and graduation rates. https://nces.ed.gov/programs/coe/indicator ctr.asp (accessed: 2021-01-16).

[8] Ben Jongbloed. 2008. Funding higher education: a view from Europe Center for Higher Education Policy Studies (2008).

[9] Jason Kaufman and Jay Gabler. 2004. Cultural capital and the extracurricular activities of girls and boys in the college attainment process. Poetics 32, 2 (2004), 145- 168.

[10] Nathan R Kuncel, Rachael J Kochevar, and Deniz S Ones. 2014. A metaranalysis of letters of recommendation in college and graduate admissions: Reasons for hope International fournal of Selection and Assessment 22, 1 (2014), 101-107.

[11] Juho Leinonen, Petri Ihantola, Antti Leinonen, Henrik Nygren, Jaakko Kurhila Matti Luukkainen, and Arto Hellas. 2019. Admitting Students through an Open Online Course in Programming: A Multi-year Analysis of Study Success. In
Proceedings of the 2019 ACM Conference on International Computing Education Research. 279-287.

[12] Miriam Liston, Victor Pigott, Denise Frawley, and Dawn Carroll. 2018. A study of progression in Irish higher education: 2014/15 to 2015/16. Dublin: Higher Education Authority (2018).

[13] Joshua Littenberg-Tobias and Justin Reich. 2018. Evaluating Access, Quality, and Inverted Admissions in MOOC-Based Blended Degree Pathways: A Study of the MIT Supply Chain Management MicroMasters. (2018).

[14] An Nguyen and Colleen M Lewis. 2020. Competitive Enrollment Policies in Computing Departments Negatively Predict First-Year Students' Sense of Belonging, Self-Ef cacy, and Perception of Department. In Proceedings of the 51st ACM Technical Symposium on Computer Science Education. 685-691

[15] Julie P Noble and Richard L Sawyer. 2004. Is high school GPA better than admission test scores for predicting academic success in college? College and University 79, 4 (2004), 17.

[16] Steve Olson and Donna Gerardi Riordan. 2012. Engage to Excel: Producing One Million Additional College Graduates with Degrees in Science, Technology, Engineering, and Mathematics. Report to the President. Executive Office of the President (2012).

[17] Enora Bennetot Pruvot and Thomas Estermann. 2017. University autonomy in Europe III. The Scorecard (2017).

[18] Matthew J. Savage Ruth James, Daniele Magistro, James Donaldson, Laura C. Healy, Mary Nevill, and PhilipJ. Hennis. 2020. Mental health and movement behaviour during the COVID-19 pandemic in UK university students: Prospective cohort study. Mental Health and Physical Activity 19(2020).

[19] Simon, Andrew Luxton-Reilly, Vangel V Ajanovski, Eric Fouh, Christabel Gonsalvez, Juho Leinonen, Jack Parkinson, Matthew Poole, and Neena Thota. 2019. Pass Rates in Introductory Programming and in other STEM Disciplines. In Proceedings of the Working Group Reports on Innovation and Technology in Computer Science Education. 53-71.

[20] Arto Vihavainen, Matti Luukkainen, and Jaakko Kurhila. 2013. MOOC as semester-long entrance exam. In Proceedings of the 14th annual ACM SIGITE conference on information technology education. 177-182

[21] Christopher Watson and Frederick WB Li. 2014. Failure rates in introductory programming revisited. In Proceedings of the 2014 conference on Innovation \& technology in computer science education. 39-44. 